\title{
Future proofing leadership through individual and collective thinking: a case study in building foresight
}

Sharon J Williams,

Cardiff Business School, Cardiff University, UK

Catherine McCauley-Smith*,

Teesside University Business School, Teesside University, UK

Ashley Braganza,

Brunel Business School, Brunel University, UK

Anne Clare Gillon,

Faculty of Business and Creative Industries, The University of the West of Scotland, UK

*Corresponding author: Teesside University Business School, Teesside University, Borough Road, Middlesbrough, TS1 3BA. Email c.mccauley-smith@tees.ac.uk Telephone +44 (0) 1642342908

\section{Main conclusion:}

Leadership development can be fostered through learning where individuals recognize and acknowledge themselves as an individual (self) leader and shared, collaborative group (us) of leaders and, as a result of which, foresight and reflective practice plays an integral role in helping to understand what is needed to foster such learning.

\section{Key Points:}

Collaborative learning and the forming of internal networks are key attributes to support the development of future leaders.

Individual and multiple perspectives of leadership development opportunities are valuable to provide a broader understanding of experiences and future actions.

Employers need to recognise the importance of collaborative reflection and foresight for the development of leaders. 


\section{Introduction}

The education landscape is changing significantly due to government policy and the economic climate. Consequently, education leadership and its effectiveness generally and the leadership of schools specifically are high on the national agenda (Department of Education, 2010). This study departs from functional, curricula-based school leadership and responds to the calls for more appropriate methods to address leadership (Hay and Hodgkinson, 2008) and consider new forms of leadership development (Day 2000; Cunliffe, 2002), through collaborative learning (Hemetsberger and Reinhardt, 2006), reflective practice (Cunliffe, 2002, Priestley et al., 2011), and a situated approach (Kempster and Stewart, 2010) to help cope with the changing environment.

The focal point of our study is the merger of three state schools into one purpose built school in the North East of the UK. This new school is built on one site, creating a single learning campus for students aged between 2 and 19. We use the merger of the three schools to examine the ways individuals recognize and acknowledge their leadership abilities and development. We are interested particularly in the effects of a bespoke education intervention on the development of these future leaders. The learning intervention was also designed to encourage participants to consider predictive approaches as they anticipated their future role within the new organisation. In the field of strategic foresight, predictive strategies and rational planning are central to a learning process which fosters adaption to future changes (Tsoukas and Shepherd, 2004). Thus, 
the aim of this study is to consider whether the bespoke intervention helped the participants to understand and prepare for their future leadership roles and the environment in which they were to operate. We examined their experiences from two perspectives, namely, the sense of self - individual leaders and the sense of us - the collection of participants with a view to gaining a getter insight into the future proofing of leadership.

The education intervention and the innovative organisational structure provide an interesting and novel setting in which to study the development of the future leaders. The research question for this study is:

What are the attributes of leadership development from the perspective of 'self and 'us' which help to prepare leaders for their future roles?

The case study we used to address this question assisted us to understand, in depth, the ways in which the participants perceived the learning intervention from the perspectives of individual (self) and group (us) and how these impacted on their future roles as leaders in a newly merged organisation. Specifically, our case study contributes to understanding the attributes of a leadership development intervention that assist future leaders in understanding their new roles. Using the self and us perspectives we examine the experiences. The design of intervention centred on reflective and visionary practice, both techniques associated with strategic foresight. As there is no common definition (Mietzner and Reger, 2009) we define foresight as a provision for or insight into future 
problems - the act(s) of looking forward. Briefly, the key attributes for developing future leaders from an individual perspective are: problem solving, preparing and managing change, sense of direction/perspective and self-reflection. The attributes for developing future leaders from a collective perspective are interdependence, sense of belonging, embryonic synergy, forming a network, and knowledge transfer.

The remainder of this paper is structured as follows. The introductory section is followed by a critique of the leadership development literature and the importance of foresight in terms of a collaborative leadership role and the working environment. Our theoretical framework is explained followed by details of the case study. A comprehensive discussion of the attributes is presented and finally, we draw conclusions and identify implications and limitations of this work and areas of further research.

\section{Leadership development}

Leadership theory suggests a radical shift, over time, in the nature of leadership (Avolio et al., 2009; House et al., 2004). Towards the end of the 20th and the first decade of the $21^{\text {st }}$ centuries researchers describe differences between leaders and managers (Pfeffer, 1977;

Kaiser et al. 2008). Although leadership has been the focus of research studies for decades what is meant by 'leadership' remains unclear and elusive (House et al. 2004). The literature has added to the confusion (Alimo-Metcalfe et al. 2006), with numerous conflicting and overlapping definitions, descriptions and comparisons of leadership 
models or distinctions between management/leadership (E.g.; Kotter, 1995; Conger and Kanungo, 1998; Yukl, 2005).

Tierney (1996) identified a 'sea change' in how leadership is studied and what we have learnt. He discusses the qualitative nature of leadership studies and argues that the ways in which individuals interact and share assumptions constructs organisational reality. However, very little scholarly attention is given to defining attributes of this individual or shared interaction.

Others hold a view that leadership theory has yet to fulfil its panacea promise (Osborn et al. 2002; Zaccaro and Horn, 2003; Currie et al. 2005). Nevertheless, and notwithstanding a plethora of studies, leadership remains 'de rigeur' in the $21^{\text {st }}$ century academic and business arena (Kellerman and Webster 2001) with a recent turn towards models of distributed leadership (Gronn, 2000; Bolden, 2011).

Distributed leadership promotes leadership carried out by a team and where leadership is enacted through a collective. From her recent review Harris (2009) identified a number of studies that reported a positive relationship between distributed learning and organisational change (e.g. Graetz, 2000) teacher leadership (e.g. Little, 1990) and professional learning communities (e.g. Louis and Marks, 1998). This positive relationship 
also extends to aspects of school performance (e.g. Hulpia and Devos, 2009; Leithwood and Jantzi, 2000).

Fundamental to being a leader is to understand how the leader is perceived by others (Pomeroy, 2005), to understand the network relations that connect people and to manage those relationships (Balkundi and Kilduff, 2005). According to Karp (2005), it is essential for executives and other change leaders to acknowledge that a vital focal point for any change initiative is people's capacity to develop a strategic vision and adapt to a new order. Of particular relevance to our research is that teachers are at the heart of change in schools (Leiringer and Cardellino, 2011; Priestley et al., 2011), therefore, foresight, which is conducted to gain more knowledge of future events (Mietzner and Reger, 2009), is integral to the role of the new leaders. According to Ansoff (1976) change presents "weak signals" before it occurs. He suggests these signals exist within qualitative information and intuitive discussions, which can lead to different types of enquiry and interpretation. It is the role of future leaders to be aware of these "weak signals" and to have an appreciation of collaborative working and intuitive discussions.

Priestley et al's (2011) study highlights the poor engagement of teachers in change due to a lack of 'connection between the big ideas and the fine grain of practice and the 'isolation' of teachers (p.268). Knowledge has to be 'acquired by doing and experiencing being a reflective practitioner' (Priestley et al., 2011), and that a stage needs to be set for 
reflective practices .... in order to construct shared understanding' (Ayas and Zenuik, 2001: 63). We observe that scholars are in some agreement that reflection results in change; for example, 'A learning system... our systems need to maintain their identity, and their ability to support the self-identity of those who belong to them, but they must at the same time be capable of transforming themselves' (Schon, 1973:57); reflective learning results in a changed conceptual perspective (Boyd and Fales, 1983); and critical reflection links changed awareness with changed action (Fook and Gardner, 2007). Emelo (2011) emphasises the importance of reflection to foresight. He advocates by understanding the past leaders are better placed to adapt to the future.

The above discussion of the literature shows the importance of reflexivity and foresight to the development of future leaders both as individuals and within a group. This gap attracted us to construct this research study and to develop the following research question:

What are the attributes of leadership development from the perspective of 'self and 'us' which help to prepare leaders for their future roles?

To address this question we developed a theoretical framework and explain this in the next section.

\section{Theoretical framework}


As noted earlier, we are interested in leadership development from two perspectives: Self and Us in order to understand the preparation of future leaders. To frame our discussion we adapted a framework provided by Küpers and Statler (2008). Initially this framework was developed to provide a multilevel view of leadership and wisdom. The framework integrates various knowledge systems to provide a clearer and more comprehensive picture of leadership development intervention. This assembled various dimensions into one framework (Küpers and Statler, 2008), for example, it accommodates internal/external and individual/multiple perspectives. Küpers and Statler, (2008) further develop the framework to consider four interconnected processes of intentional, behavioural, cultural and social domains. For the purpose of this paper, we have adapted the framework (see figure 1) to reflect only the core elements of this study: individual (self) and collective/multiple (us) perspectives. We have substituted the 'internal' and 'external' notation for 'reflection' and 'foresight' to represent the key dimensions of our research associated with the development of future leaders.

Insert figure 1 about here

\section{Methodology}

Case study research has a long, distinguished history and facilitates in depth data collection involving multiple sources of information and reports a case description and case based themes' (Creswell, 2007:73). Our case study focused on specific individuals as the unit of analysis, namely individuals who form a second tier of leadership known as the 
Wider Leadership Team (WLT) hierarchically situated immediately below a senior leadership team known as the Executive Leadership Team (ELT). The participants formed a cohort that was purposefully identified by the ELT. All nine members of the WLT agreed to participate in a two year learning intervention and all successfully completed their studies. The cohort was made up of six females and three males, of which eight were qualified teachers and one was a senior member of administrative staff. Their leadership roles were eight progress leaders (equivalent to assistant head teacher) from across the three schools and a Head of IT Systems. These leadership roles were new to them with most having little or no previous leadership experience other than that associated with leading curricula. The appropriate ethical approval and informed consent was obtained prior to the research starting. To provide anonymity participants are referred to as interviewee A through to I.

We triangulated data sources from organizational documents such as strategy plans and minutes of meetings, observation and semi-structured reflexive interviews with the nine participants on completion of the learning intervention. Audio-taped recordings and transcriptions of interviews, along with interviewer notes comprised a rich set of field collected data. The interviews were about forty five minutes in length and we accumulated over five hours of taped interview data.

\section{Data analysis}


The method used to analyse the interview transcripts is template thematic analysis of text (King, 2004). This approach allows for the development of conceptual themes and clustering of these themes into broader groupings (Cassell and Symon, 2004). Template analysis requires researchers to produce a list of codes or a 'template' which represents themes identified in textual data (King, 1998). An initial template is constructed in order to analyse text through a process of coding. The construction of the initial template is based upon two key signposts; the first is the research topic and the second is themes that emerge from reading the first few transcripts. The initial template employed for this research developed as the analysis progressed. The main themes were derived from the theoretical framework and the attributes that emerged from the coding of the interview data.

\section{The Case Study}

The organisational context of this study is the merger of three schools premised on the formation of a Federated Governing Body to allow a single, focussed approach to governance and remove a sense of schools operating in isolation (Priestley et al., 2011). The merger was based on the schools adopting a collaborative approach to the delivery of education based on an inclusive vision. The three schools are very different in nature, composition, design and purpose comprising of:

1. A large secondary community school and specialist Arts College; 
2. A special school and technology college that caters for the full range of pupils with special educational needs (SEN) across a wide ability range; and

3. A small primary school.

The context of the merger extends leadership development for leaders with devolved responsibilities across the three schools. The merged leadership structure comprises three layers: an executive director (ED), an executive leadership team (ELT) and a wider leadership team (WLT). The WLT is the focus of this research and the individuals in the team form the units of analysis for the case study. The ED recognised the need for the organisation to reconfigure and recombine its resources in order to adapt to internal and external changes. Future proofing the new leadership structures and developing predictive capacity were also important to the ED.

This newly merged organisation approached a local university with a view to meeting a continuing professional development (CPD) requirement. Subsequent to consultation between key stakeholders (James, 2012) a learning intervention was put in place. The requirement was to produce and provide a bespoke masters degree in leadership and change. The intervention curriculum is a combination of theoretical input, experiential learning, reflection, foresight and draws heavily from Kolb (1984). Furthermore it was facilitated through a climate that encouraged the participants to engage in conversation and reflection with each other (Cunliffe, 2002; Priestley et al., 2011; Evans, 2011). 
Specifically participants were encouraged to reflect on past working practices and environments and envision how these might change in the future under the new organisational structure. The intervention was delivered by university staff onsite at the school.

\section{Results and Discussion}

In this section we bring together our findings to explore how the intervention supported the development of the nine future leaders from individual and group perspectives. The education intervention was designed to reduce the sense of individuals operating in isolation and to build a sense of camaraderie and interdependence, thus joining up the 'individual selves' to form an integrated team of 'us'. Individual participants had a place in the organisation however, integrated leadership was fundamental to the effectiveness of leaders acting within a leadership structure designed to be collaborative and forward thinking. It was essential to maximize opportunities for critique and foresight by creating a thoroughly embodied, contextualized learning place in which participants could become open to engaging with criticality and envisioning future scenarios (Emelo, 2011).

The participants were encouraged to challenge their own and other's assumptions and consider scenarios associated with their future roles. They were expected to describe and critique their own and other's leadership praxis, to share experiences, to learn from each other and engage in good leadership conversations (Cunliffe, 2002) in a place (Leiringer 
and Cardellino, 2011) designed to facilitate learning through reflective practice (Kempster, 2009) and foresight. Using our adapted framework shown in Figure 1, we report the participant development experiences. The framework also includes examples of the learning and knowledge mechanisms used within the intervention. Our analysis identified a number of attributes required to support leadership development for individuals (self) and teams (us). As the two key approaches in the design of the intervention were reflection and foresight we use these to structure the reporting of our results. Table 1 summarises the attributes of the intervention and learning that were important to our participants as they progressed with their learning and developed as leaders.

Insert table one about here

\section{Sense of Self (Individuality)}

The accounts associated with the development of 'self' have been grouped under the two themes: foresight and reflection.

a) Foresight

Sharing experiences was purposefully selected as a characteristic of the education intervention learning strategy. Offering these types of learning experiences encourages problem solving ( Lenguick-Hall and Lenguick-Hall, 2003; Mintzberg, 2004). Collaborative learning also assists leaders to better reflect on past events and consider future options as part of a strategic vision (Emelo, 2011). The majority of interviewees referred to examples of how they had resolved leadership problems more effectively since completing the 
intervention. Part of this improved problem solving was attributed to having a clearer understanding of their role as a leader and an actionable vision of the future (Emelo, 2011). The use of scenarios helps to develop a "memory of the future" (de Geus, 1997) which individuals can draw upon when faced with a new situation. Interviewee E reported the intervention as providing a sense of direction and perspective of her purpose as a leader and fit with the organisation and her own career aspiration:

"I would say that it has definitely made me feel more conscious of what it is to be a leader ... and how a leader should go about leading and managing ... their area ... as well as ... [to] help me to have a sense of direction and perspective ... knowing what I want from my own job role and my own future aspirations" [Int E].

Similarly, Interviewee B refers to improved leadership skills and foresight enhancing her decision making process:

"I make better decisions because I understand a bit more about it now......you know...how it is supposed to work" [Int B].

The participants' appear to gain an increase in their confidence when faced with problem resolutions. The majority of interviewees commented on self assurance not only in relation to leadership issues but also preparing for and managing change, seeking opportunities for career development, communicating with peers and managers, and gaining respect and credibility within the wider organisation. In addition, some 
participants spoke of feeling less stressed and more organised in the way they manage their work and teams:

"I worry less now and am much more confident when dealing with leadership issues... I think I am quite hard on myself and now I realize that actually I am better than I thought" [Int. I].

Throughout the intervention the participants were able to challenge taken for granted concepts of leadership and were introduced to new ways of interpreting leadership and change so that they could explore alternative scenarios and approaches that use critical management studies in a practice oriented and a more reflexive dialogic way (Ford and Harding, 2007). Some participants also recognise the value of exploring more strategic and visionary view of their roles and the change taking place in the organisation.

"I think part of it is because you can reflect on yourself as a leader again ... thinking about yourself but also there's a range of tools that I know now are out there" [Int D].

I think just, just a wider appreciation ... of how there are bigger issues in management" [Int H].

\section{b) Reflection}

Self-reflexivity was an important element of understanding the development of participants. We recognized the embodied, 'reflexive dialogical' nature of the learning process by focusing on developing the participants' critical practice from within 
experience (Cunliffe, 2002, p. 42; Priestley et al., 2011). The opportunity throughout the intervention, to reflect upon their role and their new theoretical knowledge, encouraged the participants to consider their leadership roles, how they conversed with and related to others and how they would deal with future situations and changes:

"Before I started the [intervention] I didn't really see my leadership role......I mean.... well, I knew that I was a leader but a leader of what exactly. Now I know that there is so much more to it especially all the different models and styles and when I reflect on that I realize that it is different all the time and that you need to use different stuff for different people" [Int I].

The participants were encouraged to recount their lived experiences to provide perspectives as critical management thinkers and discover a clearer understanding of their history, which assists with visioning the future (Copeland, 2006). The participants recognised the value of reflexive skills, as one participant explained what this meant to her personally as well as her wider leadership role:

"I think its ... forced me to reflect and think about myself as a leader and how ... I view myself but also I am very conscious of other people's perceptions" [Int D].

\section{Sense of us (Collectivity)}


a) Foresight

The learning intervention was designed to encourage collaboration and relationship building (Hitt and Ireland, 2002; Mintzberg, 2004). At the beginning of the intervention participants were encouraged to 'practice and develop learning capabilities of understanding interdependence' (Ayas and Zenuik, 2001: 63). The opportunity to study with their peers was viewed positively by the group. Several of the participants reported a sense of belonging, interdependence and synergy:

"It has certainly brought us all together. I felt quite isolated when I first started ... but the course made me realize that we were all in a similar position. What was really nice was how we developed as a group and there is quite a bond now. It was really good to be able to talk to other members of staff about similar problems and being able to come up with solutions... sharing experiences really helped to build bridges". [Int I]

"... I think that even just having that time to spend talking to each other, listening to each other ... you know seeking each others' views, understanding how things work ... among different colleagues that's really helped ...that sense of community ... I think that's strengthened even though we are not meeting as a group any more ... in this context I think that bond is still there between us ... something that I think won't go" [Int E].

The multiple perspectives were important to enable participants to reflect on their past and present realities and trends in order to help with envisioning future situations and actions (Emelo, 2011). One participant suggested that the team was building supportive relationships and spreading to what can be termed as a network and sense of oneness. Similarly, one interviewee spoke about it being easier to communicate and work both inside and outside of the organisation: 
"... obviously with speaking to other people in the [organisation] I think it's helped to promote both what we [own team] do and what other people do in the [organisation]. "...I think we're much more rounded in what we do and our portfolio of what we do with schools both in the [organisation] and externally is, is much, much better in terms of ... moving forward" [Int F].

Another participant described the value of the development opportunity in terms of strengthening strategic vision and foresight.

"It has given me a broader awareness of how, how the wider elements of the school leadership and the different elements of the schoolwork together and ... how to approach those different elements in different ways depending on the outcomes that I want so its caused me to think deeper about, about the way that I would do that certainly" [Int G].

The tension of reconciling leadership development from the sense of self with the sense of the team (us) was described by one interviewee as controversial. She first questioned her own leadership skills and then those of her managers. She referred to it being " $a$ battle of wills" and envisioning how to fit and work within the organisational structure.

"... initially when I first started the [intervention] I found it ... made me quite controversial, it made me start to look more at my leadership style and sort of confront how I was dealing with things so it made me question my own leadership skills but then it also made me question ...the people who led me ... so it was sort of a battle of wills of where did I fit in the structure, how could I fit in the structure ... and work within the structure?" [Int A]. 
Interviewee $\mathrm{G}$ spoke of the frustration of not always being able to implement what he had learnt. He spoke of his role being operational and a lack of time and space to think strategically. Day-to-day survival was described as a priority and hence the opportunity to put theory into practice was very limited. Interestingly the comment here conflicts with his previous view and demonstrates a real tension and frustration about barriers to putting learning into praxis:

\footnotetext{
"My role is still very much operational ...that I don't often get the chance to think beyond that, other than day to day survival really so in terms of how I'm actually putting it in to practice I would probably say it's very limited" [lnt G].
}

Emelo (2011) advocates the intentional grouping of people with different perspectives. He sees this as a constructive way of evaluating past events and eliciting multiple options for future working and strategic vision.

\section{b) Reflection}

Time was allocated within the programme to enable the group to discuss and review leadership development within their wider role as the WLT. As all members were present at the intervention this provided the opportunity to reflect on past experiences and recent events within the School and relate these to theoretical perspectives of leadership development. Initially, the group reflective discussions were not always viewed as a learning opportunity by all participants. This was a skill that was developed and improved as the learning intervention progressed. Outside of the intervention, the participants 
found their WLT meetings provided an opportunity to reflect upon their learning and working relationships.

"We've become a really good group ourselves...and it has certainly developed working relationships amongst us in that group" [Int C].

This development intervention with the WLT team has presented the early beginnings of a foresight network (Emelo, 2011). The collaborative and reflective discussions of the group presented a broader view of the role of the WLT, their role within the organisation and the strategic intent and vision for the future.

\section{Conclusions and recommendations}

This study focuses on a leadership development education intervention for nine participants from a newly merged educational organisation. Over a two-year post graduate intervention we observed a change in the participants. They developed from a group of teachers and an IT specialist to acknowledge themselves as leaders and members of an integrated, connected and collaborative network of leader- practitioners. Their sense of self led to clarity and confirmation about their individual roles as leader and they developed a heightened sense of their own actions and those of others around them. The participants developed from being unsure about their individual leader identity to recognizing and acknowledging their place as leaders and able work with others within a newly formed leadership structure designed to operate collaboratively. They developed individual and collaborative leadership skills, they are able to understand the nuances of 
leadership language and to see the 'bigger picture' (Priestley et al., 2011). In terms of future proofing leadership within the organisation, the applicants have progressed in their collaborative working as the WLT to detect changes and predict and solve problems.

This case study offers important insights into how learning can take place and how leadership development can be fostered through a bespoke learning intervention. We were interested to find out how a bespoke learning intervention contributes to how individuals recognize and acknowledge themselves as an individual (self) leader and shared, collaborative group (us) of leaders. As a result foresight and reflective practice played an integral role in helping to understand what is needed to foster such learning.

The limitation of this study, although conducted over a two year period, is the small sample of participants. There is a need to expand this study to consider other educational sites employing the same or similar leadership development interventions so that comparative data can be gathered. We intend to conduct further research with the existing cohort to investigate whether the foresight and reflective practice continue to shape the future practice of the Wider Leadership Team.

The implications of this research are twofold: First, the practical implications are for those involved in the design of learning interventions to consider the importance of foresight and reflection in the development of leaders from both single and multiple perspectives. 
The inclusion of collaborative evaluation of past experiences and trends help to identify actions for the future. This study emphasises for employers the importance of individual and collective reflection and the need for those in leadership roles to embrace and embed visionary and reflexive skills within their learning and management practice.

Second, the theoretical implications for the future are around such questions as how will leadership behaviour manifest in the longer term, how will the leaders articulate their learning, are foresight and reflection key skills for future leaders, what is the role of internal and external networks in developing future leaders and their ability to identify 'weak signals' of change?

Our study contributes to the wider understanding of leadership development by observing a bespoke learning intervention in situ. We conclude that leadership development requires individuals to discover aspects of themselves (self) and to reflect on their relationships (us). The exploration of this intervention has demonstrated the value of reflecting on past events and envisioning future actions when developing future leaders. 
Sharon Williams is an Improvement Science Fellow with the Health Foundation and a Lecturer with the Logistics and Operations Management Section at Cardiff Business School. Prior to joining Cardiff Sharon was an Assistant Professor at Warwick Medical School, where she was instrumental in the design and delivery of a number of improvement courses for healthcare professionals and managers. Her current research interests include clinical and business systems improvement, leading and managing transformation, change and improvement, and process, organisation and supply chain/pathway redesign. Sharon can be contacted at Cardiff University and by email: wiiliamsS78@cardiff.ac.uk

Catherine McCauley-Smith previously served a full service career in the Royal Air Force as an HR manager and is currently employed by Teesside University Business School. Her research interests are in leadership, leadership development and change. She is Chair and Co-Track Chair for the British Academy of Management Organisational Transformation, Change and Development Special Interest Group. Catherine can be contacted at Teesside University and by email: c.mccauley-smith@tees.ac.uk

Ashley Braganza works at the Brunel Business School. His research and consultancy interests encompass change management, strategy implementation, process and knowledge management and transformation-enabled information systems. He has published over 120 papers in prestigious academic journals and conferences and three books. He is the Founder of the British Academy of Management's Special Interest Group in Organisational Transformation, Change and Development. He has carried out over fifty consultancy assignments with large global organisations. Ashley can be contacted at Brunel University and by email: ashley.braganza@brunel.ac.uk

Anne Clare Gillon is a lecturer in Management at The University of the West of Scotland, having previously spent 25 years in senior roles in the HR profession. Her areas of expertise and research interests are: Organisation Development, Organisational Change, Leadership, Management and across the full range of HRM subjects. She has a particular interest in pedagogical improvement and carries out CPD training for early career academics in that field. Anne Clare is the Vice Chair (elect 2015) Special Interest Groups for the British Academy of Management. Anne Clare can be contacted at UWS, Paisley site and by email: anneclare.gillon@uws.ac.uk 


\section{References}

Ansoff H. 1976. Managing strategic surprise by response to weak signals. California Management Review 1976; 18: 21-33.

Avolio B, Walumbwa F, Weber T. 2009. Leadership: Current Theories, Research and Future Directions. Annual Review of Psychology 2009; 60: 421-449.

Ayas K, Zunuik N. 2001. Project based learning: Building Communities of Reflective Practitioners. Management Learning 2001; 32: 61-76.

Balkundi P, Kilduff M. 2005. The ties that lead: A social network approach to leadership. The Leadership Quarterly 2005; 16: 941-961.

Bolden R. 2011. Distributed leadership in organisations: A review of theory and research. International Journal of Management Reviews 2011; 13: 251-269.

Boyd E, Fales A. 1983. Reflective learning: key to learning from experience. Journal of Human Psychology 1983; 23: 99-77.

Cassell C, Symon G. (eds) 2004. Essential guide to qualitative methods in organisational research, Sage Publications: London.

Conger J, Kanungo R. 1998. Charismatic Leadership in Organisations. Sage Publications: Thousand Oaks, CA.

Copeland D. 2006. Preparing the team for strategic-foresight work. The Futurist 2006; September-October: 23-24.

Creswell J. 2007. Qualitative Inquiry \& Research Design choosing among five approaches $\left(2^{\text {nd }} E d\right)$. Sage Publications: London.

Cunliffe A. 2002. Reflexive Dialogical Practice in Management Learning. Management Learning 2012; 33: 35-61.

Cunliffe A, Linstead S. 2009. Introduction: Teaching from Critical Perspectives. Management Learning 2009; 40: 5-9.

Currie G, Boyett I, Suhomlinova O. 2005. Transformational leadership within secondary schools in England: Panacea for organisational ills? Public Administration 2005; 83: 265296. 
Day D. 2000. Leadership development: a review in context. Leadership Quarterly 2000; 1: 581-611.

de Geus A. 1997. The Living Company. Harvard Business School Press; Boston, MA.

Department of Education. 2010. The importance of teaching - The schools white paper 2010, Department of Education: London.

Dexter B, Prince C. 2007. Turning managers into leaders: assessing the organisational impact of leadership development. Strategic Change 2007; 16: 217-226.

Emulo R. 2011. Strategic Foresight: See and sizing emerging opportunities. Leadership Foresight 2011; March: 8.

Evans, L. 2011. The 'shape' of teacher professionalism in England: professional standards, performance management. Professional development and the changes proposed in the 2010 White Paper. British Educational Research Journal 2011; 37: 851-870.

Fook J, Gardner, F. 2007. Practising Critical Reflection: A Resource Handbook. Open University Press: Maidenhead.

Ford J, Harding N. 2007. Move over Management we are all leaders now. Management Learning 2007; 38: 475-493.

Graetz F. 2000. Strategic change leadership. Management Decisions 2000; 38: 550-562.

Grey C, Knights D, Willmott H. 1996. Is a Critical Pedagogy of Management Possible? In Rethinking Management Education, R French and Grey C (eds). Sage Publications: London.

Gronn P. 2000. Distributed properties: a new architecture for leadership. Educational Management Administration \& Leadership 2000; 28: 317-338.

Harris A. 2009. Distributed leadership: what we know. In Harris A (ed). Distributed Leadership: Different Perspectives, Springer: Dordrecht; pp. 11-21.

Hay A, Hodgkinson M. 2008. More success than Meets the Eye - A Challenge to Critiques of the MBA Possibilities for Critical Management Education? Management Learning 2008; 39: 21-40.

Hemetsberger A, Rheinhardt C. 2006. Learning and Knowledge-building in Open-source Communities. Management Learning 2006; 37: 187-214. 
Hitt M, Ireland R. 2002. The essence of strategic leadership: Managing human and social capital. Journal of Leadership and Organisational Studies 2002; 9: 13-14.

House R, Jandan M, Dorfman P, Gupta, V (eds). 2004. Culture, leadership and organizations: The GLOBE study of 62 societies. Sage Publications: Thousand Oakes, CA.

Hulpia H, Devos G. 2009. Exploring the link between distributed leadership and job satisfaction of school leaders. Educational Studies 2009; 35: 153-171.

James M. 2012. Growing confidence in educational research: threats and opportunities. British Educational Research Journal; 2012; 38: 181-201.

Kaiser R, Hogan R, Bartholomew C. 2008. Leadership and the fate of organizations. American Psychologist 2008; 6: 96-110.

Karp T. 2005. Unpacking the Mysteries of Change: Mental Modelling. Journal of Change Management 2005; 5: 87-96.

Kempster S. 2009. How Managers have learnt to Lead: Exploring the development of leadership practice. Palgrave Macmillan: Basingstoke.

Kempster S, Stewart J. 2010. Becoming a leader: A co-produced autoethnographic exploration of situated learning of leadership practice. Management Learning 2010; 41: 205-219.

Kellerman B, Webster S. 2001. The recent literature on public leadership reviewed and considered. The Leadership Quarterly 2001; 12: 485-514.

King N. 1998. Template Analysis in Qualitative Methods and Analysis in Organisational Research, Symon G and Cassell C (eds). Sage Publications: London.

King N. 2004. Using templates in the thematic analysis of text in Essential Guide to Qualitative Methods in Organisational Research, Symon G and Cassell C (eds). Sage Publications: London.

Kolb D. 1984. Experiential learning: Experience as the source of learning and development. Prentice Hall: New Jersey.

Kotter J. 1995. Leading Change: Why Transformation Efforts Fail. Harvard Business Review 1995; 73: 59-67. 
Küpers W, Statler M. 2008. Practically wise leadership: toward an integral understanding. Culture and Organisation 2008; 14: 379-400.

Leiringer R, Cardellino P. 2011. Schools for the twenty first century: school design and educational transformation. British Educational Research Journal 2011; 37: 915-934.

Leithwood K, Jantzi D. 2000. The effects of different sources of leadership on student engagement in school. In Leadership for Change and School Reform, Riley K and Louis K (eds), Routledge: London, 50-66.

Little JW. 1990. The persistence of privacy: autonomy and initiative in teachers' professional relations. Teachers College Record, 1990; 91: 509-536.

Louis KS, Marks H. 1998. Does professional community affect the classroom? Teachers' work and student work in restructuring schools. American Educational Research Journal 1998; 33: 757-798.

Mietzner D, Reger G. 2009. Practices of strategic foresight in biotech companies. International Journal of Innovation Management 2009; 13: 273-294.

Mintzberg H. 2004. Managers Not MBAs A Hard Look at the Soft Practice of Managing and Management Development, Berrell-Koehler Publishers: San Francisco.

Osborn R, Hunt J, Jauch L. 2002. Towards a contextual theory of leadership. The Leadership Quarterly 2002; 13: 797-837.

Pfeffer J. 1977. The Ambiguity of Leadership. The Academy of Management Review 1977; 2: $104-112$.

Pomeroy A. 2005. Head of the class. HR Magazine 2005; 50: 54-58

Priestley M, Millar K, Barrett L, Wallace C. 2011. Teacher learning communities and educational change in Scotland: the Highland experience. British Educational Research Journal 2011; 37: 265-284.

Tierney W. 1996. Leadership and Postmodernism: on voice and qualitative method. Leadership Quarterly 1996; 7: 371-383.

Yin R. 2003. Case Study Research: Design and Method (3 ${ }^{\text {rd }}$ ed), Sage Publications: Thousand Oaks, CA. 
Yukl G. 2005. Assessing the construct validity and utility of two new influence tactics. Journal of Organisational Behaviour 2005; 26: 705-725.

Zaccaro S, Horn Z. 2003. Leadership theory and practice: Fostering an effective symbiosi. The Leadership Quarterly, 2003; 14: 769-806. 